\title{
Certain Environmental Conditions Maximize Ammonium Accumulation and Minimize Nitrogen Loss During Nitrate Reduction Process by Pseudomonas putida Y-9
}

\author{
Xuejiao Huang ${ }^{1,2 *}$, Wenzhou Tie ${ }^{1}$, Deti Xie ${ }^{2}$, Daihua Jiang ${ }^{1}$ and Zhenlun Li ${ }^{2 *}$ \\ ${ }^{1}$ Key Laboratory of (Guang Xi) Agricultural Environment and Products Safety, College of Agronomy, Guangxi University, \\ Nanning, China, ${ }^{2}$ Chongqing Key Laboratory of Soil Multiscale Interfacial Process, Southwest University, Chongqing, China
}

OPEN ACCESS

Edited by:

Qiaoyun Huang,

Huazhong Agricultural University,

China

Reviewed by:

Jin-tian Li,

South China Normal University, China

Ang Li,

Harbin Institute of Technology, China

${ }^{*}$ Correspondence:

Zhenlun $\mathrm{Li}$

lizhlun4740@sina.com

Xuejiao Huang

hxuejiao0412@sina.com

Specialty section:

This article was submitted to

Microbiotechnology,

a section of the journal

Frontiers in Microbiology

Received: 25 August 2021 Accepted: 11 November 2021 Published: 13 December 2021

Citation:

Huang X, Tie WZ, Xie DT, Jiang

$D H$ and $L i Z L$ (2021) Certain Environmental Conditions Maximize

Ammonium Accumulation and Minimize Nitrogen Loss During

Nitrate Reduction Process by

Pseudomonas putida Y-9.

Front. Microbiol. 12:764241. doi: 10.3389/fmicb.2021.764241
Realizing the smallest nitrogen loss is a challenge in the nitrate reduction process. Dissimilatory nitrate reduction to ammonium (DNRA) and nitrate assimilation play crucial roles in nitrogen retention. In this study, the effects of the carbon source, $\mathrm{C} / \mathrm{N}$ ratio, $\mathrm{pH}$, and dissolved oxygen on the multiple nitrate reduction pathways conducted by Pseudomonas putida Y-9 are explored. Strain Y-9 efficiently removed nitrate (up to 89.79\%) with glucose as the sole carbon source, and the nitrogen loss in this system was $15.43 \%$. The total nitrogen decrease and ammonium accumulation at a $\mathrm{C} / \mathrm{N}$ ratio of 9 were lower than that at 12 and higher than that at 15, respectively $(P<0.05)$. Besides, neutral and alkaline conditions ( $\mathrm{pH} 7-9)$ favored nitrate reduction. Largest nitrate removal (81.78\%) and minimum nitrogen loss (10.63\%) were observed at $\mathrm{pH} 7$. The nitrate removal and ammonium production efficiencies of strain Y-9 increased due to an increased shaking speed. The expression patterns of nirBD (the gene that controls nitrate assimilation and DNRA) in strain Y-9 were similar to ammonium patterns of the tested incubation conditions. In summary, the following conditions facilitated nitrate assimilation and DNRA by strain Y-9, while reducing the denitrification: glucose as the carbon source, a $\mathrm{C} / \mathrm{N}$ ratio of 9 , a $\mathrm{pH}$ of 7 , and a shaking speed of $150 \mathrm{rpm}$. Under these conditions, nitrate removal was substantial, and nitrogen loss from the system was minimal.

Keywords: Pseudomonas putida Y-9, nitrate reduction, carbon source, $\mathrm{C} / \mathrm{N}$ ratios, $\mathrm{pH}$, dissolved oxygen, nirBD expression

\section{HIGHLIGHTS}

The roles of DNRA and assimilatory reduction during $\mathrm{NO}_{3}{ }^{-}$removal and nitrogen conservation in soils have been insufficiently examined. Moreover, the effects of environmental factors on the $\mathrm{NO}_{3}{ }^{-}$reduction process when the three $\mathrm{NO}_{3}{ }^{-}$reduction pathways (denitrification, DNRA, and assimilation) coexist remain unclear. In this study, the effect of the carbon source, $\mathrm{C} / \mathrm{N}$ ratio, $\mathrm{pH}$, and dissolved oxygen on ammonium accumulation and the expression of nirBD in strain Y-9 are explored during the nitrate reduction processes. The following conditions facilitated nitrate assimilation and DNRA by strain Y-9 while simultaneously reducing denitrification: glucose as the carbon source, a $\mathrm{C} / \mathrm{N}$ ratio of 9 , a $\mathrm{pH}$ of 7 , and a shaking speed of $150 \mathrm{rpm}$. Under these conditions, nitrate removal was substantial, and nitrogen loss from the system was 
minimal. These findings provide theoretical support for technical studies of nitrate removal and nitrogen retention in soils.

\section{INTRODUCTION}

Large amounts of industrial fertilizers are often applied to crops to increase crop yields. This leads to the considerable accumulation of nitrate $\left(\mathrm{NO}_{3}{ }^{-}\right)$in the soil (Kraft et al., 2014). $\mathrm{NO}_{3}{ }^{-}$, a mobile anion, is prone to loss by denitrification or runoff into surface waters, and this not only decreases the efficiency of nitrogen fertilizers but also has various passive environmental impacts including water eutrophication and greenhouse gas (nitrous oxide, $\mathrm{N}_{2} \mathrm{O}$ ) emissions (Beeckman et al., 2018; Li et al., 2018; Sánchez and Minamisawa, 2019; Xia et al., 2020). The ammonium $\left(\mathrm{NH}_{4}{ }^{+}\right)$, produced by the dissimilatory reduction of $\mathrm{NO}_{3}{ }^{-}$to $\mathrm{NH}_{4}{ }^{+}$(DNRA) via microorganismal respiration, can be adsorbed by soil colloids and then utilized by crops (Song et al., 2014; Zhang et al., 2015; Pandey et al., 2019). Similarly, the microbial assimilatory reduction of $\mathrm{NO}_{3}{ }^{-}$can reduce $\mathrm{NO}_{3}{ }^{-}$ to $\mathrm{NH}_{4}{ }^{+}$via $\mathrm{NO}_{2}{ }^{-}$catalyzed by the relative reductase. Then, the $\mathrm{NH}_{4}{ }^{+}$is incorporated into biomolecules and used by the bacterium. After death, the microorganisms release the $\mathrm{NH}_{4}{ }^{+}$ via mineralization for plant use (Shao et al., 2011; Wang et al., 2020). It is clear that DNRA and $\mathrm{NO}_{3}{ }^{-}$assimilation ease the accumulation of $\mathrm{NO}_{3}{ }^{-}$in agricultural soils and improve the efficiency of nitrogen fertilizers. These processes reduce the risk of $\mathrm{NO}_{3}{ }^{-}$loss and mitigate the adverse effects of nitrogen fertilizer use. Several recent studies have investigated the role of DNRA in soil nitrogen conservation in farmlands (Shan et al., 2016; Friedl et al., 2018). Yet, the important role of assimilatory $\mathrm{NO}_{3}{ }^{-}$ reduction in $\mathrm{NO}_{3}{ }^{-}$removal and nitrogen conservation in soils has been comparatively neglected.

Several environmental factors, including the $\mathrm{C} / \mathrm{N}$ ratio, oxygen concentration, carbon source, affect enzyme activity in microorganisms by controlling the expression of relevant genes (e.g., amoA, hao, narG, and nirK) and thus impacting nitrogen cycles (Szukics et al., 2010; Ke et al., 2013; Caranto and Lancaster, 2017; Yu et al., 2019). Thus, we speculated that soil $\mathrm{NO}_{3}{ }^{-}$ removal could be maximized and soil nitrogen loss could be minimized by adjusting certain external environmental factors to enhance $\mathrm{NO}_{3}{ }^{-}$assimilation and DNRA while decreasing denitrification. Typically, higher $\mathrm{C} / \mathrm{N}$ ratios favor DNRA over denitrification (Kraft et al., 2014; Yoon et al., 2015; Van den Berg et al., 2016; Putz et al., 2018). Some studies have reported that glucose addition improved the $\mathrm{NO}_{3}{ }^{-}$assimilation capacity of the soil (Recous et al., 1990; Romero et al., 2015). However, the effects of environmental factors on the $\mathrm{NO}_{3}{ }^{-}$reduction process when the three $\mathrm{NO}_{3}{ }^{-}$reduction pathways coexist are unclear.

Pseudomonas putida Y-9 performs $\mathrm{NO}_{3}{ }^{-}$assimilation, DNRA, and denitrification under aerobic conditions simultaneously. The gene nirBD has been shown to control the assimilation and DNRA process (Huang et al., 2020). In this study, we investigate the effects of the carbon source, $\mathrm{C} / \mathrm{N}$ ratio, $\mathrm{pH}$, and dissolved oxygen (DO) on the accumulation of ammonium in the medium and the expression of nirBD in strain Y-9 during the nitrate reduction process. This study focuses on adjusting the environmental factor parameters to enhance the DNRA and $\mathrm{NO}_{3}{ }^{-}$assimilation of strain Y-9. The results will provide theoretical support for technical research on $\mathrm{NO}_{3}{ }^{-}$removal and nitrogen retention in soil.

\section{MATERIALS AND METHODS}

\section{Microorganisms and the Culture Media}

P. putida Y-9 (Genbank No. KP410740), which performs $\mathrm{NO}_{3}{ }^{-}$assimilation, denitrification, and DNRA under aerobic conditions simultaneously (Huang et al., 2020), was used in this study.

A denitrification medium (DM) was used to assess the nitrate reduction abilities of strain Y-9. The DM (per liter,

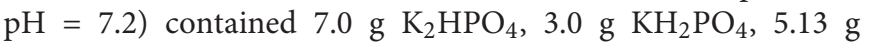
$\mathrm{CH}_{3} \mathrm{COONa}, 0.10 \mathrm{~g} \mathrm{MgSO}_{4} \cdot 7 \mathrm{H}_{2} \mathrm{O}, 0.72 \mathrm{~g} \mathrm{KNO}_{3}$, and $0.05 \mathrm{~g}$ $\mathrm{FeSO}_{4} \cdot 7 \mathrm{H}_{2} \mathrm{O}$. Luria-Bertani (LB) medium used for bacterial enrichment contained $10 \mathrm{~g} \mathrm{NaCl}, 10 \mathrm{~g}$ tryptone, and $5 \mathrm{~g}$ yeast extract per liter (per liter, $\mathrm{pH}$ 7.0-7.2). All of the mediums were autoclaved for $30 \mathrm{~min}$ at $121^{\circ} \mathrm{C}$.

\section{Effects of the Different Factors on Nitrate Reduction}

The preserved strain Y-9 bacteria were activated in the LB medium at $150 \mathrm{rpm}$ and $15^{\circ} \mathrm{C}$ for $36 \mathrm{~h}$. Cells in the logarithmic growth phase were inoculated into a DM medium to assess the effects of the carbon source, $\mathrm{C} / \mathrm{N}$ ratio, $\mathrm{pH}$, and $\mathrm{DO}$ on Y-9-driven $\mathrm{NO}_{3}{ }^{-}$reduction (Li et al., 2019; Yan et al., 2021).

In the carbon source experiments, one of the three carbon sources (sodium acetate, glucose, or sodium citrate) was added to $100 \mathrm{~mL}$ of $\mathrm{DM}$ medium. The $\mathrm{C} / \mathrm{N}$ ratio, $\mathrm{pH}$, and shaking speed were kept constant at 15,7 , and $150 \mathrm{rpm}$, respectively. In the $\mathrm{C} / \mathrm{N}$ ratio experiments, $100 \mathrm{~mL}$ aliquots of the $\mathrm{DM}$ medium were amended with glucose to yield $\mathrm{C} / \mathrm{N}$ ratios of $3,6,9,12$, or 15 . The $\mathrm{pH}$ and shaking speed were kept constant at 7 and $150 \mathrm{rpm}$, respectively. In the $\mathrm{pH}$ experiments, the initial $\mathrm{pH}$ was adjusted using $\mathrm{NaOH}$ and $\mathrm{HCl}$ to $4,6,7,8$, or 9. The carbon source was glucose, and the $\mathrm{C} / \mathrm{N}$ ratio and shaking speed were held constant at 9 and $150 \mathrm{rpm}$, respectively. To determine the effects of DO on $\mathrm{NO}_{3}{ }^{-}$reduction, the shaking speed was set to $0,50,100,150$, or $180 \mathrm{rpm}$ according to previous studies (Ren et al., 2014; Lei et al., 2019; Chen et al., 2021; Yan et al., 2021). The carbon source was glucose, and the $\mathrm{C} / \mathrm{N}$ ratio and $\mathrm{pH}$ were kept constant at 9 and 7 , respectively. The cultures were incubated at $15^{\circ} \mathrm{C}$ for $4 \mathrm{~d}$. All of the above experiments were performed in triplicate. Samples were taken every day from each system. The optical density at $600 \mathrm{~nm}$ $\left(\mathrm{OD}_{600}\right), \mathrm{NH}_{4}{ }^{+}, \mathrm{NO}_{3}{ }^{-}$, and total nitrogen (TN) were measured for each sample.

\section{Kinetic Analysis of Nitrate Degradation}

The modified Compertz model was used to describe the kinetics analysis of nitrate degradation by strain Y-9 (Chen et al., 2016). The kinetic equation was $\mathrm{y}=\mathrm{y}_{0}\left(1-\exp \left(-\exp \left(\frac{\mathrm{e} R_{m}}{\mathrm{y}_{0}}\left(\mathrm{t}_{0}-\mathrm{t}\right) 1\right)\right)\right)$, where $\mathrm{y}$ is the $\mathrm{NO}_{3}{ }^{-}$ 
concentration at different incubation times $(\mathrm{mg} / \mathrm{L})$; $\mathrm{y}_{0}$ is the initial concentration of $\mathrm{NO}_{3}^{-}(\mathrm{mg} / \mathrm{L}), R_{\mathrm{m}}$ is the maximum conversion rate $(\mathrm{mg} / \mathrm{L} / \mathrm{h}), \mathrm{t}_{0}$ is the lag time $(\mathrm{h}), \mathrm{t}$ is the reaction time $(\mathrm{h})$, and $\mathrm{e}$ is the mathematical constant.

\section{Expression of nirBD in Strain Y-9}

Total RNA was extracted from strain Y-9 after 4 $\mathrm{d}$ of incubation under various conditions using a Trizol extraction kit (Invitrogen, United States), following the manufacturer's instructions. The specific primers B1/B2 (F: CGCAACCATCTGCTCGTGT; R: CTGGCGGGTGTAGGAAAAGT) were designed based on the nirBD gene sequence (GenBank, MK561362). These primers were used to amplify the nirBD gene from the isolates. The $16 \mathrm{~S}$ rRNA gene was used as an internal standard, as structural rRNA is present in cells at reasonably constant levels under normal growth conditions (Edwards and Saunders, 2010). The 16S rRNA gene was amplified using the forward primer GAACGCTAATACCGCATACGTCC and the reverse primer ATCATCCTCTCAGACCAGTTAC. The total RNA was reversetranscribed using the RevertAid first-strand cDNA synthesis kit following the manufacturer's instructions. Real-time quantitative PCRs were performed using the $\mathrm{SYBR}^{\circledR}$ Premix Ex Taq ${ }^{\mathrm{TM}}$ II. Each real-time PCR was performed in triplicate. The PCR cycling conditions were as follows: initial denaturation at $95^{\circ} \mathrm{C}$ for $30 \mathrm{~s}$; 38 cycles of $95^{\circ} \mathrm{C}$ for $15 \mathrm{~s}, 60^{\circ} \mathrm{C}$ for $30 \mathrm{~s}$, and $72^{\circ} \mathrm{C}$ for $30 \mathrm{~s} ; 1$ cycle of $95^{\circ} \mathrm{C}$ for $15 \mathrm{~s}$; and, finally, stepwise temperature increases from $55^{\circ} \mathrm{C}$ to $95^{\circ} \mathrm{C}$ to generate the melting curve. Standard curves were established using a dilution series of pMD19-T vectors containing the target gene.

\section{Analytical Methods}

The $\mathrm{OD}_{600}$ was determined based on the absorbance at $600 \mathrm{~nm}$, which was measured using a spectrophotometer. The contents of the different forms of nitrogen were determined as described by Huang et al. (2019). TN was measured in the suspension. The concentration of $\mathrm{NH}_{4}{ }^{+}, \mathrm{NO}_{3}{ }^{-}$, and $\mathrm{NO}_{2}{ }^{-}$was measured in the supernatant, which was obtained by centrifuging each sample at $8,000 \mathrm{rpm}$ for $5 \mathrm{~min}$. Three replicates were analyzed per sample, and the results are presented as means \pm the standard deviation of the mean (SD). The $\mathrm{TN}$ and $\mathrm{NO}_{3}{ }^{-}$removal efficiencies were calculated as follows: $R_{V}=\left(\mathrm{T}_{1}-\mathrm{T}_{2}\right) / \mathrm{T}_{1} \times 100 \%$, where $R_{\mathrm{v}}$

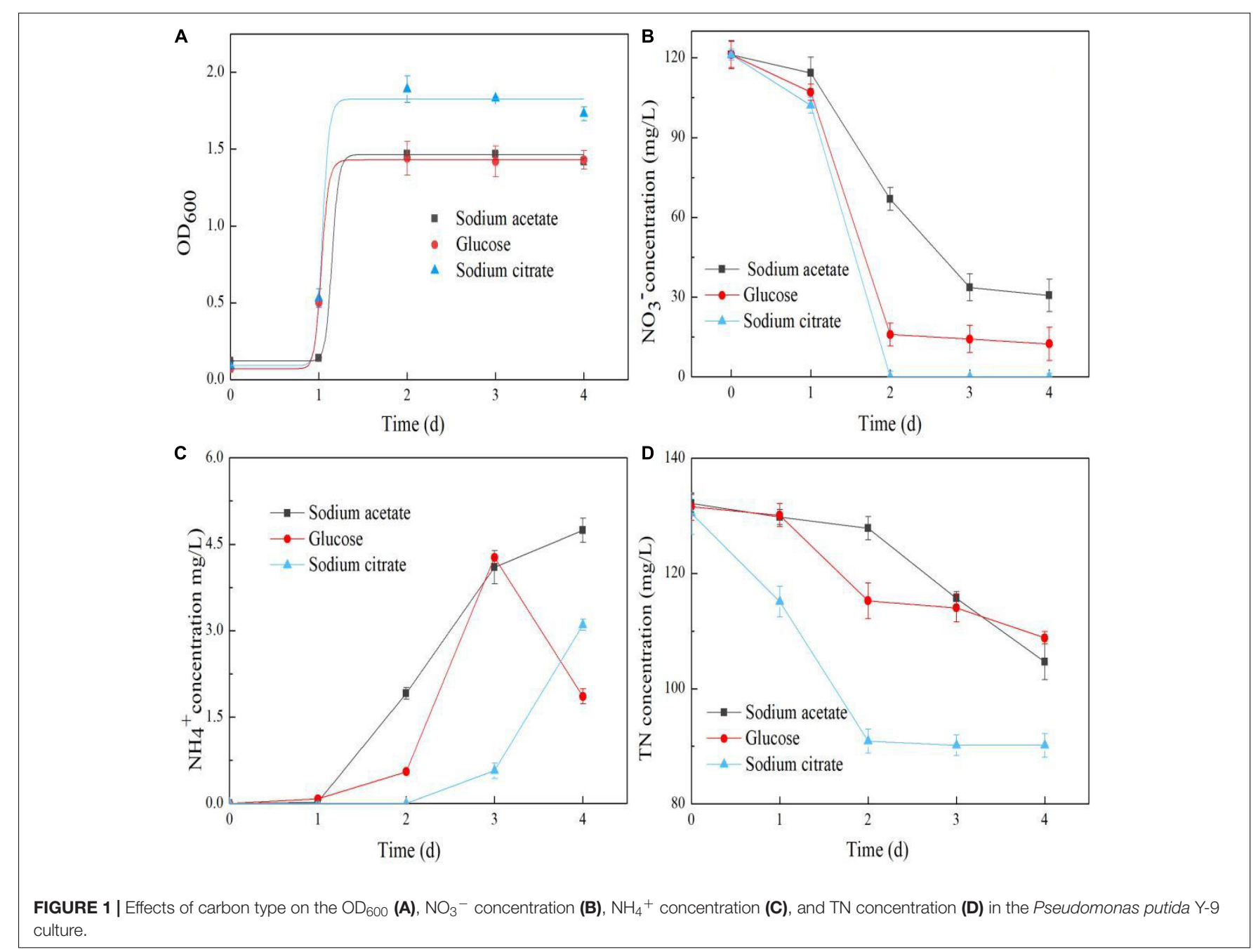


is the removal efficiency of $\mathrm{TN}$ or $\mathrm{NO}_{3}{ }^{-}(\%)$, and $\mathrm{T}_{1}$ and $\mathrm{T}_{2}$ are the initial and final concentrations of $\mathrm{TN}$ or $\mathrm{NO}_{3}{ }^{-}$in the system, respectively.

\section{Statistical Analyses}

One-way analyses of variance (ANOVAs), followed by Duncan's Multiple Range Tests were performed using SPSS 22, and the differences among means were considered statistically significant at $P<0.05$. Graphs were drawn using Origin 8.6 and GraphPad Prism 6.

\section{RESULTS AND DISCUSSION}

\section{Effects of the Carbon Source on Nitrate Reduction}

A carbon source is typically essential for the growth of heterotrophic microorganisms, and it acts as an electron donor for nitrogen cycling (Sun et al., 2016). In this study, strain Y-9 grew vigorously and reached the stationary cell growth phase after $2 \mathrm{~d}$ when sodium acetate, glucose, or sodium citrate was used as the sole carbon source (Figure 1A). Moreover, sodium acetate, glucose, and sodium citrate were suitable carbon sources for $\mathrm{NO}_{3}{ }^{-}$removal, with removal efficiencies of $74.75,89.79$, and $100 \%$, respectively, at $4 \mathrm{~d}$ (Figure 1B). These results were consistent with those of Guo et al. (2016), who reported that sodium acetate, glucose, and sodium citrate enhanced the $\mathrm{NO}_{3}{ }^{-}$removal capacity of Enterobacter cloacae strain HNR. Furthermore, the nitrate degradation rate followed the modified Compertz model $\left(R^{2}>0.90\right)$, and the maximum $\mathrm{NO}_{3}{ }^{-}$conversion rates were $1.60,4.92$, and $44.35 \mathrm{mg} / \mathrm{L} / \mathrm{h}$ in media containing sodium acetate, glucose, and sodium citrate, respectively (Table $\mathbf{1}$ ).

Previous results have shown that strain Y-9 performs DNRA and nitrate assimilation under aerobic conditions (Huang et al., 2020). Based on the duration of cultivation (4 d), the detectable $\mathrm{NH}_{4}{ }^{+}$in the supernatant might have resulted from DNRA and nitrate assimilation followed by mineralization (Figure 1C). It is worth noting that after $3 \mathrm{~d}$ of cultivation, when all the cells were in the stationary phase, the detectable $\mathrm{NH}_{4}{ }^{+}$began to decrease in the glucose-containing system. However, it continued to increase in the media containing sodium acetate and sodium citrate. These results demonstrated that $\mathrm{NO}_{3}{ }^{-}$reduction by strain $\mathrm{Y}-9$ differed when glucose was the sole carbon source compared to the other two carbon sources.

The TN decreases in our system were due to the denitrification activities of strain Y-9, and nirBD in strain Y-9 controls DNRA and nitrate assimilation (Huang et al., 2020). The TN in the media supplemented with different carbon sources tended to decrease (Figure 1D). The maximum TN decrease $(60.27 \mathrm{mg} / \mathrm{L})$ was found in the sodium citrate-containing medium, and the minimum TN decrease occurred $(22.77 \mathrm{mg} / \mathrm{L})$ in the glucose medium. This was in accordance with data from Yang et al. (2012) who reported that Pseudomonas stutzeri D6 most effectively removed TN when sodium citrate was the carbon source. Moreover, the nirBD expression level in strain Y-9 peaked when glucose was the carbon source (Figure 2). These findings demonstrated that glucose addition promoted DNRA and nitrate assimilation, effectively removing most of the $\mathrm{NO}_{3}{ }^{-}$from the system (up to $89.79 \%$ ) while inhibiting denitrification (i.e., the total nitrogen lost from the system was $22.77 \mathrm{mg} / \mathrm{L}$ ).

\section{Effects of the C/N Ratio on Nitrate Reduction}

The effects of the $\mathrm{C} / \mathrm{N}$ ratio on the nitrate reduction conducted by strain Y-9 were further studied. Strain Y-9 growth improved as

TABLE 1 | Kinetic parameters and final removal efficiency for the degradation of nitrate by strain Y-9 under different environmental conditions.

\begin{tabular}{|c|c|c|c|c|c|}
\hline & $\begin{array}{l}\text { Environmental } \\
\text { factor }\end{array}$ & $\begin{array}{l}R_{\mathrm{m}} \\
(\mathrm{mg} / \mathrm{L} / \mathrm{h})\end{array}$ & $t_{0}(h)$ & $R^{2}$ & $\begin{array}{c}\text { The last nitrate removal } \\
\text { efficiency }(\%)\end{array}$ \\
\hline \multirow{4}{*}{$\begin{array}{l}\text { Carbon } \\
\text { sources }\end{array}$} & Sodium acetate & 1.6 & 20.97 & 0.94 & 74.14 \\
\hline & & & & & \\
\hline & Glucose & 4.92 & 23.99 & 0.97 & 89.79 \\
\hline & Sodium citrate & 44.35 & 23.82 & 1 & 100 \\
\hline \multirow[t]{5}{*}{$\mathrm{C} / \mathrm{N}$} & 3 & 0.44 & 9.35 & 0.69 & 30.46 \\
\hline & 6 & 0.58 & -21.1 & 0.64 & 54 \\
\hline & 9 & 1.91 & 5.17 & 0.9 & 81.78 \\
\hline & 12 & 5.44 & 16.99 & 0.99 & 100 \\
\hline & 15 & 3 & 11.68 & 0.97 & 89.79 \\
\hline \multirow[t]{5}{*}{$\mathrm{pH}$} & 4 & -1.63 & -3177.13 & -3.21 & 4.99 \\
\hline & 6 & 0.8 & -7.7 & 0.74 & 58.27 \\
\hline & 7 & 2.05 & 4.87 & 0.90 & 81.78 \\
\hline & 8 & 1.91 & 10.99 & 0.87 & 80.57 \\
\hline & 9 & 1.5 & 6.04 & 0.87 & 79.14 \\
\hline \multirow{5}{*}{$\begin{array}{l}\text { Shaking } \\
\text { speed }\end{array}$} & 0 & 1.33 & 38.7 & 0.97 & 69.9 \\
\hline & 50 & 1.03 & 6.756 & 0.93 & 71.47 \\
\hline & 100 & 1.41 & 3.4 & 0.83 & 71.18 \\
\hline & 150 & 1.90 & 3.17 & 0.89 & 81.78 \\
\hline & 180 & 1.68 & 26.96 & 0.93 & 76.17 \\
\hline
\end{tabular}

In $\mathrm{C} / \mathrm{N}, \mathrm{pH}$ and shaking speed, glucose was chosen as carbon source.

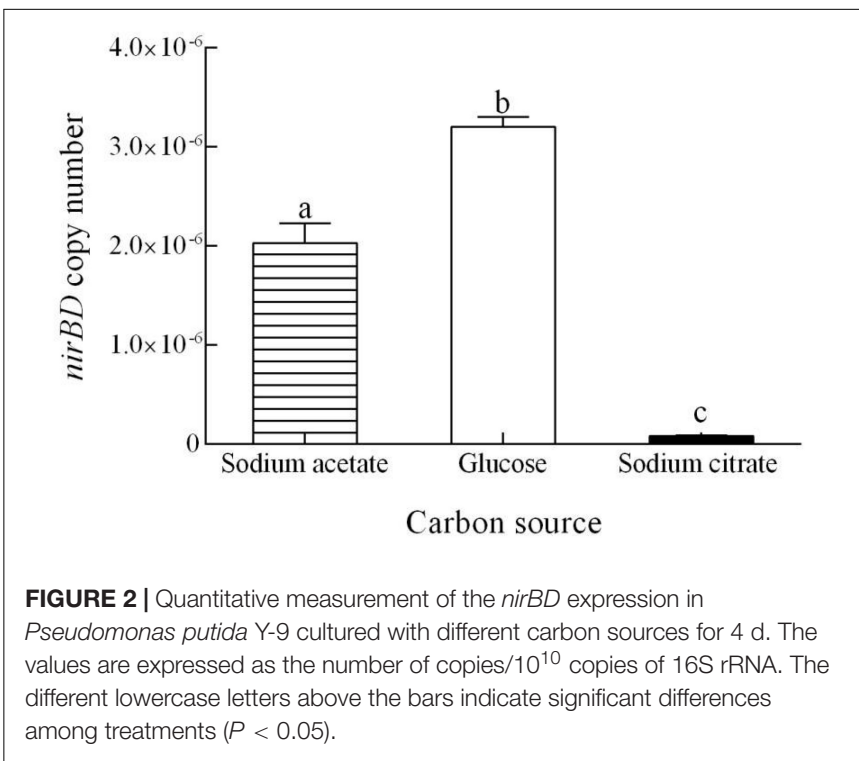


the $\mathrm{C} / \mathrm{N}$ ratio increased (Figure 3A). This result was consistent with previous studies (Kim et al., 2008; Liu et al., 2016), that the growth of $P$. putida AD-21 and Marinobacter strain NNA5 increased as the relative proportion of carbon increased in the medium. This might have been because electron transfer slowed when carbon concentrations were low, providing insufficient energy for microbial growth (Kim et al., 2008; Zhao et al., 2018). Greater than $80 \%$ of the $\mathrm{NO}_{3}{ }^{-}$was removed at $\mathrm{C} / \mathrm{N}$ ratios of 9-15. However, the removal efficiency of $\mathrm{NO}_{3}{ }^{-}$did not exceed 30.46 and $54.00 \%$ when the $\mathrm{C} / \mathrm{N}$ ratio was 3 and 6 , respectively (Figure 3B). Furthermore, nitrate degradation rates at $\mathrm{C} / \mathrm{N}$ ratios of 9-15 were consistent with the predictions of the modified Compertz model $\left(R^{2}>0.90\right)$, and the $\mathrm{NO}_{3}{ }^{-}$conversion rate was maximum at a $\mathrm{C} / \mathrm{N}$ ratio of 12 (Table $\mathbf{1}$ ).

The decrease of $\mathrm{TN}$ in this system generally mirrored the change in $\mathrm{NO}_{3}{ }^{-}$(Figure 3D). The reduction in $\mathrm{TN}$ at the extremely high $\mathrm{C} / \mathrm{N}$ ratio of 15 was lower than the reduction in $\mathrm{TN}$ at a $\mathrm{C} / \mathrm{N}$ ratio of 12 , suggesting that a $\mathrm{C} / \mathrm{N}$ ratio of 12 was optimal for denitrification. Our results indicated that the influences of $\mathrm{C} / \mathrm{N}$ ratios on Y-9-driven denitrification agreed with many previous studies. They showed that extremely low or high carbon concentrations suppressed microorganismal denitrification (Kim et al., 2008; Guo et al., 2016; Zhao et al., 2018). $\mathrm{NH}_{4}+$ concentration in the supernatant initially increased and then decreased during $\mathrm{NO}_{3}{ }^{-}$reduction (Figure $3 \mathrm{C}$ ), consistent with our carbon source analysis (Figure 1C). When the $\mathrm{C} / \mathrm{N}$ ratio was 9, strain Y-9 removed most of the $\mathrm{NO}_{3}{ }^{-}$(removal efficiency $81.78 \%$ ) via DNRA and $\mathrm{NO}_{3}{ }^{-}$assimilation (nirBD in strain Y-9 was most strongly expressed (Figure 4)). Notably, the denitrification performance of strain $\mathrm{Y}-9$ at a $\mathrm{C} / \mathrm{N}$ ratio of 9 was significantly weaker than that at a $\mathrm{C} / \mathrm{N}$ ratio of $12(P<0.05)$.

\section{Effects of the Initial pH on Nitrate Reduction}

The impacts of the initial $\mathrm{pH}$ on the nitrate reduction performance of strain Y-9 are shown in Figure 5. At an
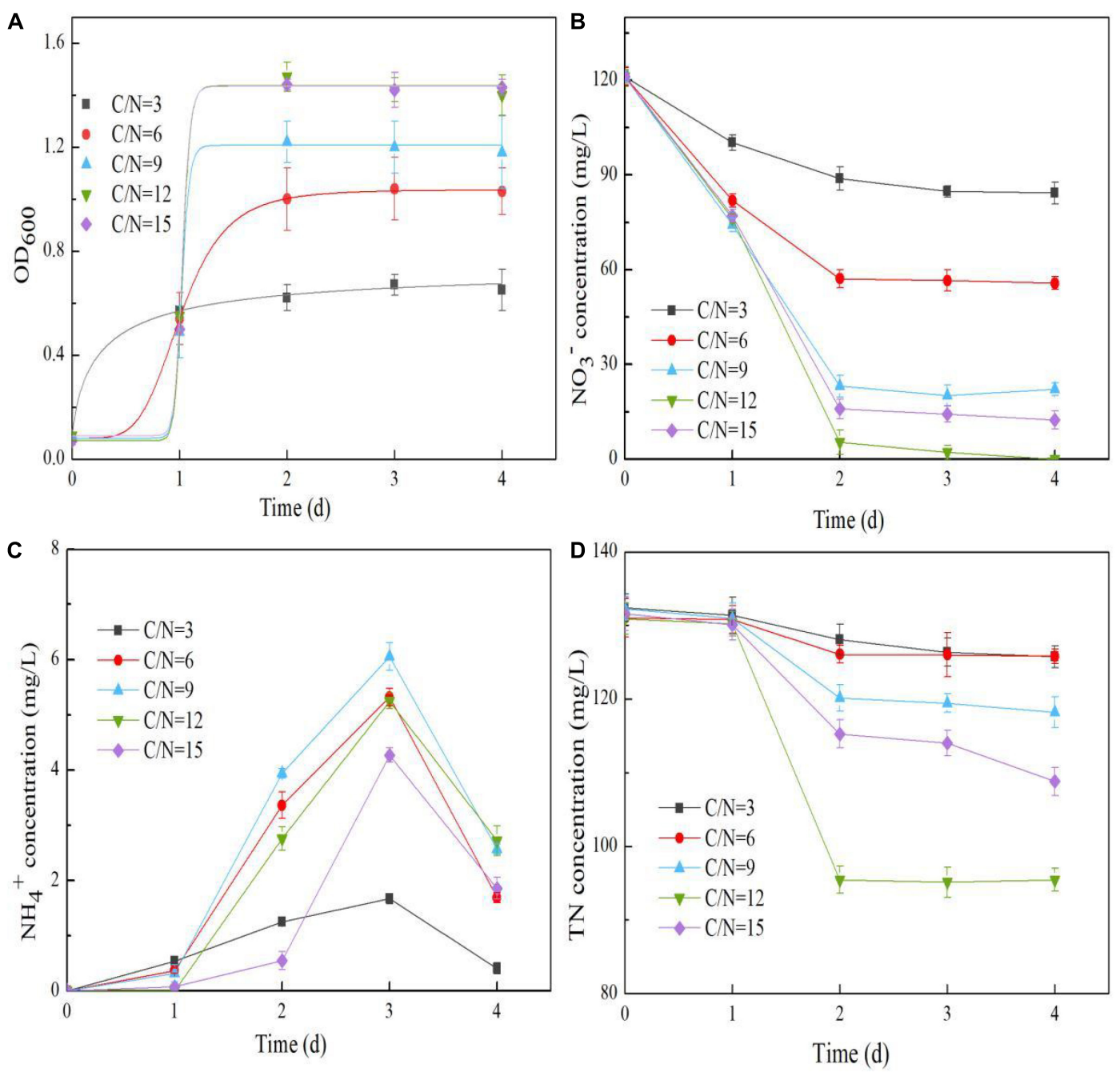

FIGURE 3 | Effects of the $\mathrm{C} / \mathrm{N}$ ratio on the $\mathrm{OD}_{600}$ (A), $\mathrm{NO}_{3}{ }^{-}$concentration (B), $\mathrm{NH}_{4}{ }^{+}$concentration (C), and TN concentration (D) in the Pseudomonas putida Y-9 culture with glucose as the sole carbon source. 


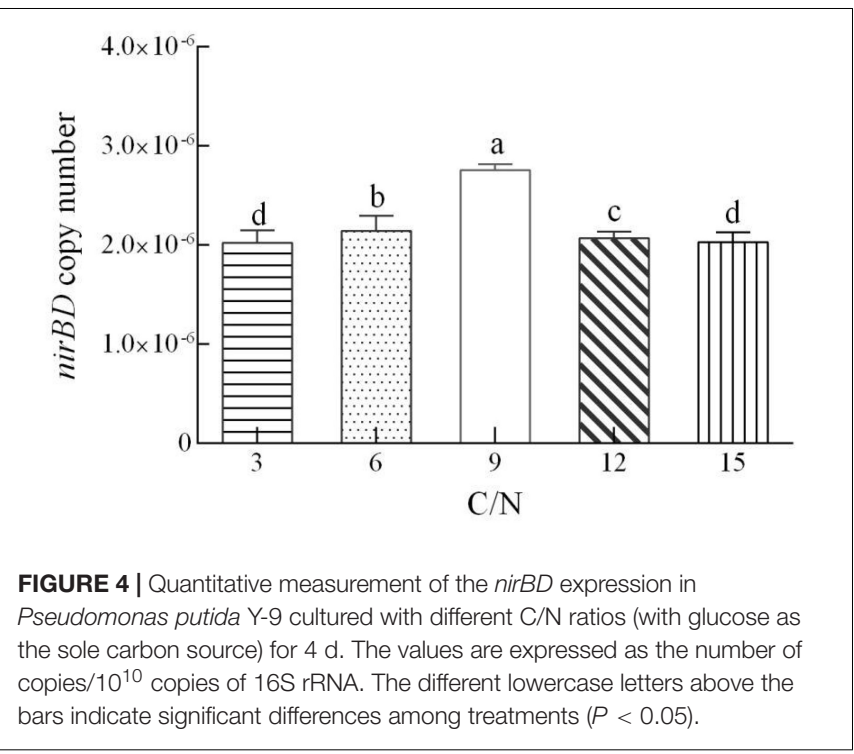

initial $\mathrm{pH}$ of 4 , the bacterial density did not noticeably increase, and $\mathrm{NO}_{3}{ }^{-}$reduction was minimal throughout the experiment (Figures 5A,B), suggesting that an overly acidic environment was detrimental to these bacteria. However, in the $\mathrm{pH}$ range $7-9$, strain growth and $\mathrm{NO}_{3}{ }^{-}$removal were significantly improved $(P<0.05)$ (Figures $\mathbf{5 A}, \mathbf{B})$. These results are in agreement with the general finding that neutral or alkaline environments are beneficial for bacteria growth and bacterium-driven $\mathrm{NO}_{3}{ }^{-}$removal (Li et al., 2017; Rout et al., 2017). The $\mathrm{NO}_{3}{ }^{-}$removal efficiency was significantly positively correlated with the growth of strain Y-9 $(P<0.01)$ (Figure 5), indicating that $\mathrm{pH}$ might control the $\mathrm{NO}_{3}{ }^{-}$removal efficiency by influencing the growth of strain Y-9. However, this possibility requires further study. The TN concentration in the suspension decreased as the initial $\mathrm{pH}$ increased, and the TN decreased by $35.01 \mathrm{mg} / \mathrm{L}$ at $\mathrm{pH} 9$ (Figure 5D). This indicated that alkaline environments favored the denitrification in strain Y-9 under aerobic conditions.

After $3 \mathrm{~d}$ of culture, a negligible amount of $\mathrm{NH}_{4}{ }^{+}$was detected at $\mathrm{pH}$ 4. However, the accumulation of $\mathrm{NH}_{4}{ }^{+}$at $\mathrm{pH}$ 7-9 was higher than $5.0 \mathrm{mg} / \mathrm{L}$ (Figure 5C). At the end of the experiment, the nirBD expression level in strain Y-9 at $\mathrm{pH}$ 7-9 was better than at $\mathrm{pH} 4$ or 6 (Figure 6). These results showed that the initial $\mathrm{pH}$ affected the expression of nirBD in strain Y-9, and this might influence $\mathrm{NH}_{4}{ }^{+}$ production from DNRA and $\mathrm{NO}_{3}{ }^{-}$assimilation as well
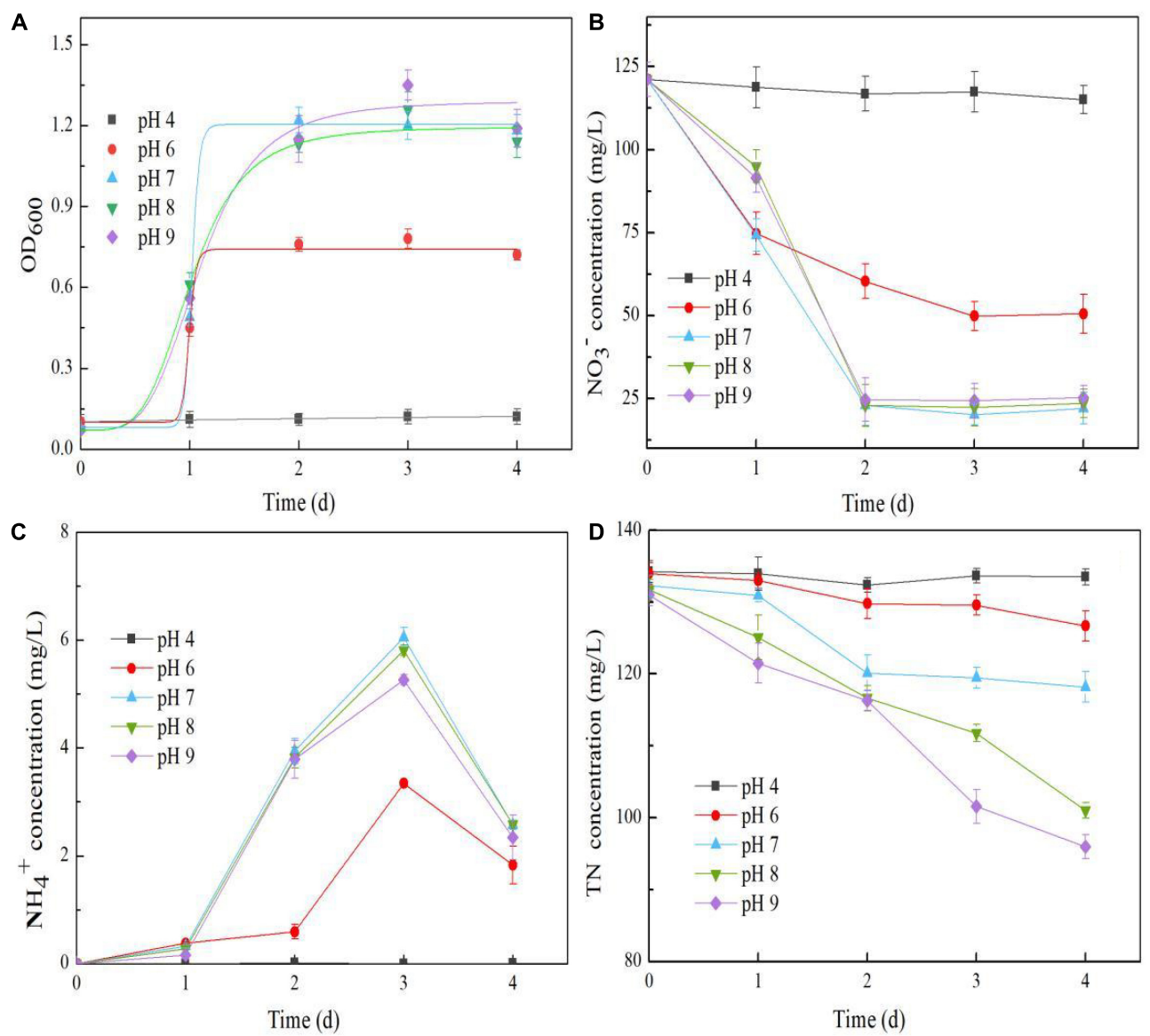

FIGURE 5 | Effects of $\mathrm{pH}$ on the $\mathrm{OD}_{600}$ (A), $\mathrm{NO}_{3}{ }^{-}$concentration (B), $\mathrm{NH}_{4}{ }^{+}$concentration (C), and TN concentration (D) in the Pseudomonas putida Y-9 culture with glucose as the carbon source. 


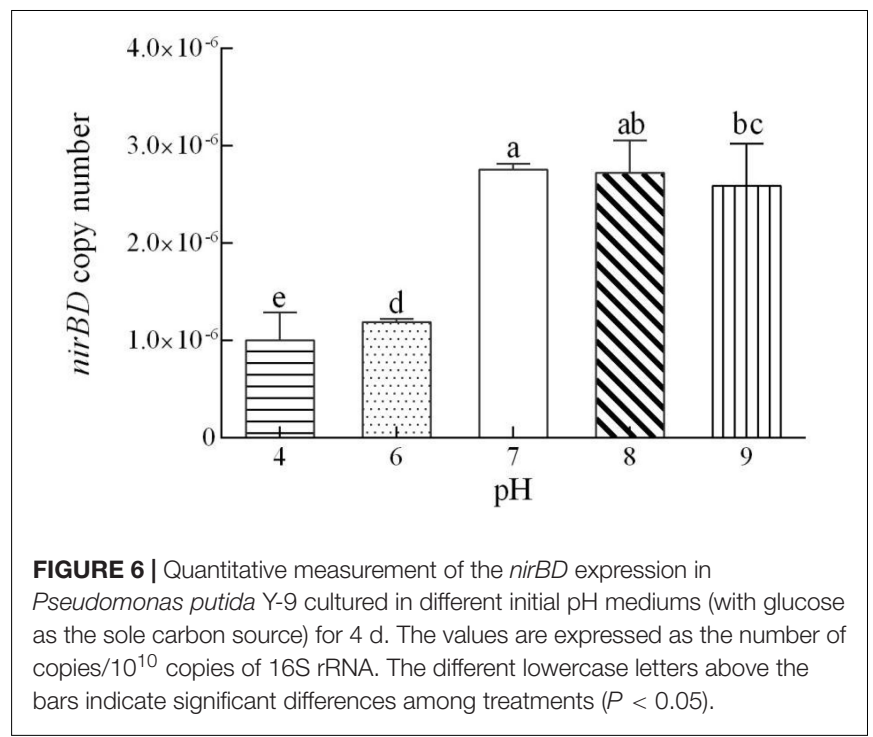

as its subsequent mineralization (Huang et al., 2020). The results of previous studies on the effects of $\mathrm{pH}$ on $\mathrm{NO}_{3}{ }^{-}$ reduction by soil microorganisms are widely contradictory
(Nägele and Conrad, 1990; Stevens et al., 1998). Here, strain Y-9 effectively performed $\mathrm{NO}_{3}{ }^{-}$assimilation, DNRA, and denitrification at $\mathrm{pH}$ 7-9. This finding was inconsistent with a previous study (Yoon et al., 2015) that suggested that a low $\mathrm{pH}$ was more favorable for denitrification, while a high $\mathrm{pH}$ promoted the production of $\mathrm{NH}_{4}{ }^{+}$via DNRA. This discrepancy indicated that the effects of $\mathrm{pH}$ on the microbial nitrogen cycle were complex and required further study. Our results suggested that a neutral $\mathrm{pH}$ was most favorable for $\mathrm{NO}_{3}{ }^{-}$removal and nitrogen retention.

\section{Effects of Dissolved Oxygen on Nitrate Reduction}

Strain Y-9 growth and $\mathrm{NO}_{3}{ }^{-}$reduction increased gradually as the shaking speed increased (Figures $7 \mathbf{A}, \mathbf{B}$ ). Changes in the $\mathrm{NO}_{3}{ }^{-}$degradation rates at various rotating speeds were consistent with the predictions of the modified Compertz model $\left(R^{2}>0.80\right)$, and the $\mathrm{NO}_{3}{ }^{-}$conversion rate achieved its maximum at $150 \mathrm{rpm}$ (Table 1). These results suggested that increasingly aerobic conditions improved strain growth and $\mathrm{NO}_{3}{ }^{-}$reduction. TN decreased gradually throughout the incubation process, irrespective of the DO concentration.
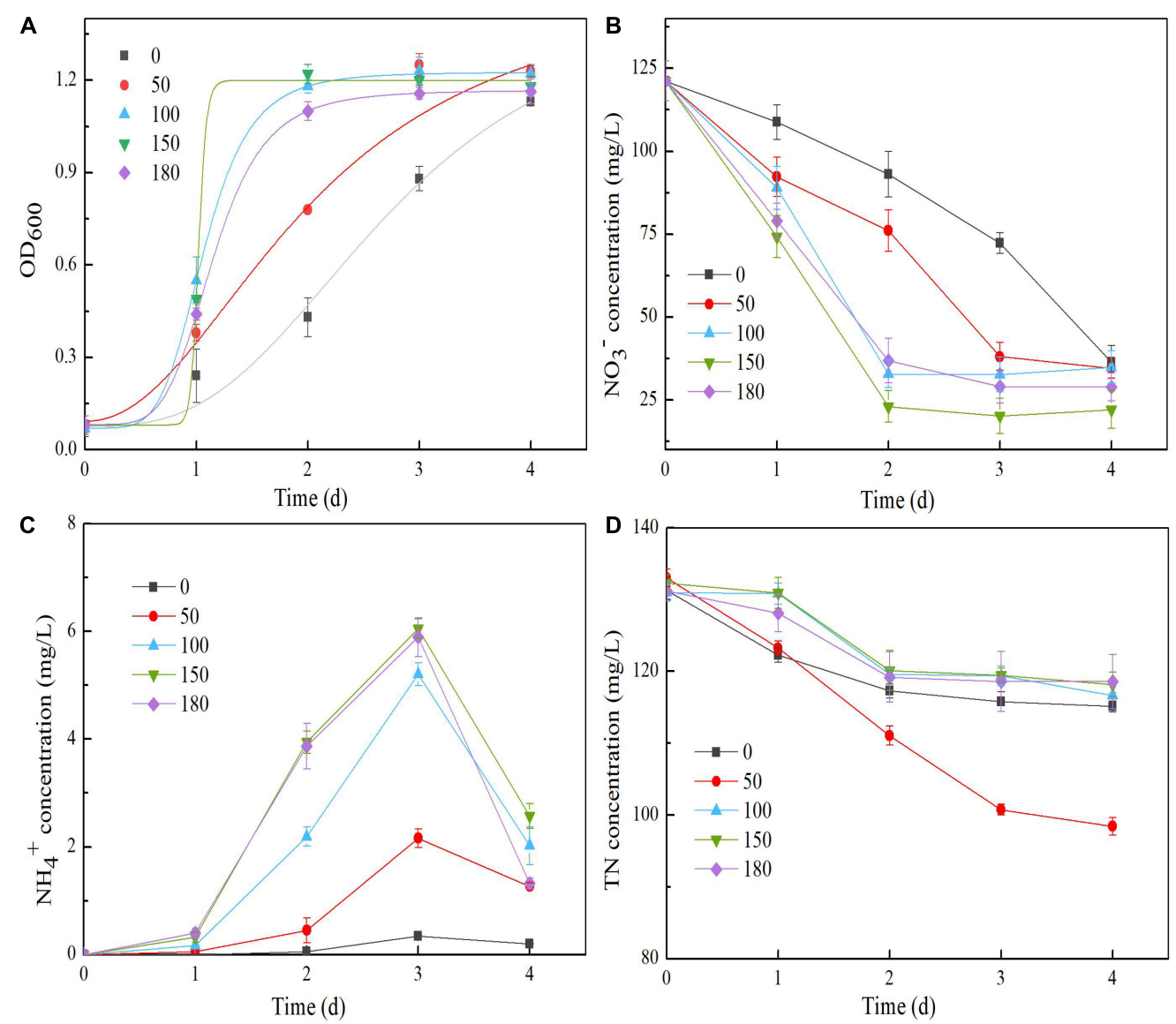

FIGURE 7 | Effects of shaking speed on the $\mathrm{OD}_{600}(\mathbf{A}), \mathrm{NO}_{3}{ }^{-}$concentration (B), $\mathrm{NH}_{4}{ }^{+}$concentration (C), and TN concentration (D) in the Pseudomonas putida Y-9 culture with glucose as the sole carbon source. 
However, TN decreased at low shaking speeds $(\leq 50 \mathrm{rpm})$ was significantly greater than those at high shaking speeds $(\geq 100 \mathrm{rpm}) \quad(P<0.05)$. The decrease in the $\mathrm{TN}$ at the end of the experiment reached the maximum $(34.58 \mathrm{mg} / \mathrm{L})$ at a shaking speed of $50 \mathrm{rpm}$ (Figure 7D). These results suggested that the denitrification performance of strain Y-9 first increased and then decreased as the DO concentration increased. This finding was consistent with the results of Zhao et al. (2018); Rout et al. (2017), and Huang and Tseng (2001). Previous studies demonstrated that the denitrification performance remained stable as long as the DO concentration remained within a fixed range. Nevertheless, the denitrification enzyme activity levels improved noticeably when the DO concentration decreased below a threshold value (Song et al., 2011). For strain Y-9, 50 rpm might be the threshold DO value that affects denitrification enzymes, although this possibility requires further testing.

The quantitative PCR amplification results indicated that the expression of nirBD increased with an increase in the shaking speed (Figure 8). These results, in conjunction with the $\mathrm{NO}_{3}{ }^{-}$reduction performance of strain Y-9 (Huang et al, 2020), indicated that high DO concentrations stimulated the expression of nirBD in strain Y-9, promoting $\mathrm{NO}_{3}{ }^{-}$ assimilation as well as DNRA, and thus releasing more $\mathrm{NH}_{4}{ }^{+}$into the supernatant (Figure 7C). Consistent with this, Yang et al. (2012) and Zhao et al. (2018) found that $\mathrm{NH}_{4}{ }^{+}$production increased with the DO content during $\mathrm{NO}_{3}$ - reduction by $P$. stutzeri D6 and P. stutzeri strain XL2. Variance analyses indicated that the amounts of $\mathrm{NO}_{3}{ }^{-}$ removal from the culture media and $\mathrm{NH}_{4}{ }^{+}$accumulated in the culture media at high shaking speeds $(\geq 100 \mathrm{rpm})$ differed obviously from those at low rotation speeds $(\leq 50 \mathrm{rpm})$ $(P<0.05)$. These results indicated that good aeration effectively promoted $\mathrm{NO}_{3}{ }^{-}$removal and $\mathrm{NH}_{4}{ }^{+}$production by strain Y-9.

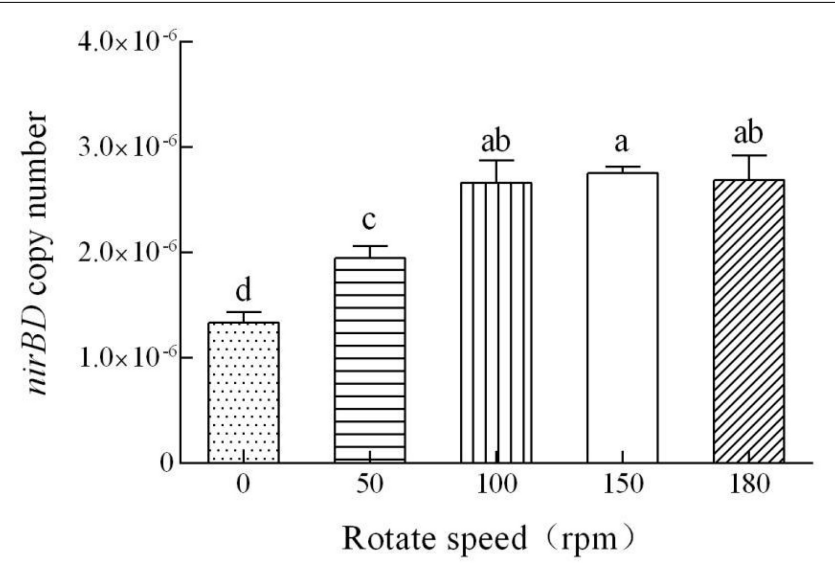

FIGURE 8 | Quantitative measurement of the nirBD expression in Pseudomonas putida Y-9 cultured at different shaking speeds (with glucose as the sole carbon source) for $4 \mathrm{~d}$. The values are expressed as the number of copies $/ 10^{10}$ copies of $16 \mathrm{~S}$ rRNA. The different lowercase letters above the bars indicate significant differences among treatments $(P<0.05)$.
The heavy application of chemical nitrogen fertilizers leads to an accumulation of highly mobile nitrate in upland soils and significantly increases the risk of nitrogen loss (Lin et al., 2020; Vidal et al., 2020). Therefore, it is essential to control $\mathrm{NO}_{3}{ }^{-}$concentrations in soil. The nitrogen cycle conducted by microorganisms plays a critical role in regulating nitrate concentrations in soil, compared to artificially limiting the application of ammonium and nitrate fertilizers (Shao et al., 2011; Song et al., 2014; Zhang et al., 2015; Pandey et al., 2019; Wang et al., 2020). Denitrification effectively removes excess $\mathrm{NO}_{3}{ }^{-}$ from soil systems but leads to nitrogen losses in the form of nitrogen gas or the greenhouse gas $\mathrm{N}_{2} \mathrm{O}$ (Stein and Klotz, 2016). For example, Putz et al. (2018) showed that approximately 70$78 \%$ of all $\mathrm{N}_{2} \mathrm{O}$ originated from denitrification in annual cereal soils. Both the DNRA and $\mathrm{NO}_{3}{ }^{-}$assimilation processes can decrease soil $\mathrm{NO}_{3}{ }^{-}$concentration and facilitate soil nitrogen conservation by reducing $\mathrm{NO}_{3}{ }^{-}$to $\mathrm{NH}_{4}{ }^{+}$via $\mathrm{NO}_{2}{ }^{-}$(Kuypers et al., 2018; Wang et al., 2020). Thus, to pursue the minimum loss of nitrogen and maximize nitrogen fertilizer efficiency, strategies that strengthen DNRA as well as $\mathrm{NO}_{3}{ }^{-}$assimilation while weakening denitrification in surface soils should be pursued. Previously, we found that strain Y-9 performs simultaneous nitrate assimilation, DNRA, and denitrification under aerobic conditions. It has also been clarified that the gene, nirBD, controls $\mathrm{NO}_{3}{ }^{-}$assimilation and DNRA process in strain Y9 (Huang et al., 2020). In this study, we further explored the environmental factors that affect the nitrate removal pathways of strain Y-9. Our results provide a theoretical reference for technical studies of nitrate removal and nitrogen conservation in farmland soils.

\section{CONCLUSION}

Four common external environmental conditions (carbon source, $\mathrm{C} / \mathrm{N}$ ratio, $\mathrm{pH}$, and dissolved oxygen) affected the nitrate reduction performance of strain Y-9. A high initial $\mathrm{pH}$ enhanced nitrate assimilation, denitrification, and the DNRA of strain Y-9.

The optimal conditions for the nitrate assimilation and the DNRA of strain Y-9 were glucose as the carbon source, C/N 9, $\mathrm{pH} 7.0$, and $150 \mathrm{rpm}$. Under these conditions, the nitrogen loss from the system was the smallest.

\section{DATA AVAILABILITY STATEMENT}

The original contributions presented in the study are included in the article/Supplementary Material, further inquiries can be directed to the corresponding authors.

\section{AUTHOR CONTRIBUTIONS}

$\mathrm{XH}$ and ZL: conceptualization. XH: methodology, data curation, visualization, supervision, and writing-original draft preparation. WT: software, formal analysis, and investigation. 
$\mathrm{XH}, \mathrm{ZL}$, and DX: validation. ZL: resources and project administration. $\mathrm{XH}, \mathrm{ZL}, \mathrm{DJ}$, and DX: writing-review and editing. $\mathrm{XH}$ and $\mathrm{ZL}$ : funding acquisition. All authors have read and agreed to the published version of the manuscript.

\section{FUNDING}

This work was supported financially by the National Natural Science Fund of China (42107333 and 42077217).

\section{REFERENCES}

Beeckman, F., Motte, H., and Beeckman, T. (2018). Nitrification in agricultural soils: impact, actors and mitigation. Curr. Opin. Biotechnol. 50, 166-173. doi: 10.1016/j.copbio.2018.01.014

Caranto, J. D., and Lancaster, K. M. (2017). Nitric oxide is an obligate bacterial nitrification intermediate produced by hydroxylamine oxidoreductase. Proc. Natl. Acad. Sci. U.S.A. 114, 8217-8222. doi: 10.1073/pnas.1704504114

Chen, J., Zhao, B., An, Q., Wang, X., and Zhang, Y. X. (2016). Kinetic characteristics and modelling of growth and substrate removal by Alcaligenes faecalis strain NR. Bioprocess Biosys. Eng. 39, 593-601. doi: 10.1007/s00449016-1541-9

Chen, J. L., Xu, J., Zhang, S. N., Liu, F., Peng, J. W., Peng, Y. X., et al. (2021). Nitrogen removal characteristics of a novel heterotrophic nitrification and aerobic denitrification bacteria, Alcaligenes faecalis strain WT14. J. Environ. Manage. 282, 111961. doi: 10.1016/j.jenvman.2021.111961

Edwards, K. J., and Saunders, N. A. (2010). Real-time PCR used to measure stressinduced changes in the expression of the genes of the alginate pathway of Pseudomonas aeruginosa. J. Appl. Microbiol. 91, 29-37. doi: 10.1046/j.13652672.2001.01339.x

Friedl, J., De Rosa, D., Rowlings, D. W., Grace, P. R., Müller, C., and Scheer, C. (2018). Dissimilatory nitrate reduction to ammonium (DNRA), not denitrification dominates nitrate reduction in subtropical pasture soils upon rewetting. Soil Biol. Biochem. 125, 340-349. doi: 10.1016/j.soilbio.2018.07.024

Guo, L. J., Zhao, B., An, Q., and Tian, M. (2016). Characteristics of a novel aerobic denitrifying bacterium, Enterobacter cloacae strain HNR. Appl. Biochem. Biotechnol. 178, 947-959. doi: 10.1007/s12010-015-1920-8

Huang, H. K., and Tseng, S. K. (2001). Nitrate reduction by Citrobacter diversus under aerobic environment. Appl. Microbiol. Biotechnol. 55, 90-94. doi: 10. $1007 / \mathrm{s} 002530000363$

Huang, X. J., Weisener, C. G., Ni, J. P., He, B. H., Xie, D. T., and Li, Z. P. (2020). Nitrate assimilation, dissimilatory nitrate reduction to ammonium, and denitrification coexist in Pseudomonas putida Y-9 under aerobic conditions. Bioresour. Technol. 312:123597. doi: 10.1016/j.biortech.2020.123597

Huang, X. J., Xu, Y., He, T. X., Jia, H. J., Feng, M., Xiang, S. D., et al. (2019). Ammonium transformed into nitrous oxide via nitric oxide by Pseudomonas putida Y-9 under aerobic conditions without hydroxylamine as intermediate. Bioresour. Technol. 277, 87-93. doi: 10.1016/j.biortech.2019.01.040

Ke, X. B., Angel, R., Lu, Y. H., and Conrad, R. (2013). Niche differentiation of ammonia oxidizers and nitrite oxidizers in rice paddy soil. Environ. Microbiol. 15, 2275-2292. doi: 10.1111/1462-2920.12098

Kim, M., Jeong, S. Y., Yoon, S. J., Cho, S. J., Kim, Y. H., Kim, M. J., et al. (2008). Aerobic denitrification of Pseudomonas putida AD-21 at different C/N Ratios. J. Biosci. Bioeng. 106, 498-502. doi: 10.1263/jbb.106.498

Kraft, B., Tegetmeyer, H. E., Sharma, R., Klotz, M. G., Ferdelman, T. G., Hettich, R. L., et al. (2014). The environmental controls that govern the end product of bacterial nitrate respiration. Science 345, 676-679. doi: 10.1126/science. 1254070

Kuypers, M. M. M., Marchant, H. K., and Kartal, B. (2018). The microbial nitrogencycling network. Nat. Rev. Microbiol. 16, 263-276. doi: 10.1038/nrmicro.2 018.9

Lei, X., Jia, Y. T., Chen, Y. C., and Hu, Y. Y. (2019). Simultaneous nitrification and denitrification without nitrite accumulation by a novel isolated Ochrobactrum

\section{ACKNOWLEDGMENTS}

We thank LetPub for its linguistic assistance during the preparation of this manuscript.

\section{SUPPLEMENTARY MATERIAL}

The Supplementary Material for this article can be found online at: https://www.frontiersin.org/articles/10.3389/fmicb. 2021.764241/full\#supplementary-material

anthropic LJ81. Bioresour. Technol. 272, 442-450. doi: 10.1016/j.biortech.2018. 10.060

Li, B., Lv, R., Xiao, Y., Hu, W., Mai, Y. L., Zhang, J. W., et al. (2019). A novel nitrite-base aerobic denitrifying bacterium Acinetobacter sp. YT03 and its transcriptome analysis. Front. Microbiol. 10:2580. doi: 10.3389/fmicb.2019. 02580

Li, Y., Chapman, S. J., Nicol, G. W., and Yao, H. (2018). Nitrification and nitrifiers in acidic soils. Soil Biol. Biochem. 116, 290-301. doi: 10.1016/j.soilbio.2017.1 0.023

Li, Y. T., Wang, Y. R., Fu, L., Gao, Y. Z., Zhao, H. X., and Zhou, W. Z. (2017). Aerobic-heterotrophic nitrogen removal through nitrate reduction and ammonium assimilation by marine bacterium Vibrio sp. Y1-5. Bioresour. Technol. 230, 103-111. doi: 10.1016/j.biortech.2017.01.049

Lin, D. R., Huang, Y. C., Zhao, J. J., Wu, Z. J., Liu, S. L., Qin, W., et al. (2020). Evaluation of seed nitrate assimilation and stimulation of phenoliclinked antioxidant on pentose phosphate pathway and nitrate reduction in three feed-plant species. BMC Plant Biol. 20:267. doi: 10.1186/s12870-020-02453-w

Liu, Y., Ai, G. M., Miao, L. L., and Liu, Z. P. (2016). Marinobacter strain NNA5, a newly isolated and highly efficient aerobic denitrifier with zero N2O emission. Bioresour. Technol. 206, 9-15. doi: 10.1016/j.biortech.2016.01.066

Nägele, W., and Conrad, R. (1990). Influence of soil pH on the nitrate-reducing microbial populations and their potential to reduce nitrate to $\mathrm{NO}$ and $\mathrm{N} 2 \mathrm{O}$. FEMS Microbiol. Lett. 74, 49-57. doi: 10.1016/0378-1097(90)90515-R

Pandey, A., Suter, H., He, J. Z., Hu, H. W., and Chen, D. (2019). Dissimilatory nitrate reduction to ammonium dominates nitrate reduction in long-term low nitrogen fertilized rice paddies. Soil Biol. Biochem. 131, 149-156. doi: 10.1016/j. soilbio.2019.01.007

Putz, M., Schleusner, P., Rütting, T., and Hallin, S. (2018). Relative abundance of denitrifying and DNRA bacteria and their activity determine nitrogen retention or loss in agricultural soil. Soil Biol. Biochem. 123, 97-104. doi: 10.1016/j.soilbio. 2018.05.006

Recous, S., Mary, B., and Faurie, G. (1990). Microbial immobilization of ammonium and nitrate in cultivated soils. Soil Biol. Biochem. 22, 913-922. doi: 10.1016/0038-0717(90)90129-N

Ren, Y. X., Yang, L., and Liang, X. (2014). The characteristics of a novel heterotrophic nitrifying and aerobic denitrifying bacterium, Acinetobacter junii YB. Bioresour. Technol. 171, 1-9. doi: 10.1016/j.biortech.2014.08.058

Romero, C. M., Engel, R., Chen, C., and Wallander, R. (2015). Microbial immobilization of nitrogen-15 labelled ammonium and nitrate in an agricultural soil. Soil Sci. Soc. Am. J. 79, 595-602. doi: 10.2136/sssaj2014.08. 0332

Rout, P. R., Bhunia, P., and Dash, R. R. (2017). Simultaneous removal of nitrogen and phosphorous from domestic wastewater using Bacillus cereus GS-5 strain exhibiting heterotrophic nitrification, aerobic denitrification and denitrifying phosphorous removal. Bioresour. Technol. 244, 484-495. doi: 10. 1016/j.biortech.2017.07.186

Sánchez, C., and Minamisawa, K. (2019). Nitrogen cycling in soybean rhizosphere: sources and sinks of nitrous oxide (N2O). Front. Microbiol. 10:1943. doi: 10. 3389/fmicb.2019.01943

Shan, J., Zhao, X., Sheng, R., Xia, Y., Ti, C., Quan, X., et al. (2016). Dissimilatory nitrate reduction processes in typical Chinese paddy soils: rates, relative contributions, and influencing factors. Environ. Sci. Technol. 50, 9972-9980. doi: $10.1021 /$ acs.est.6b01765 
Shao, Z. H., Gao, J., Ding, X. M., Wang, J., Chiao, J. S., and Zhao, G. P. (2011). Identification and functional analysis of a nitrate assimilation operon nasACKBDEF from Amycolatopsis mediterranei U32. Arch. Microbiol. 193, 463-477. doi: 10.1007/s00203-011-0690-0

Song, B., Lisa, J. A., and Tobias, C. R. (2014). Linking DNRA community structure and activity in a shallow lagoonal estuarine system. Front. Microbiol. 5:460. doi: $10.3389 /$ fmicb. 2014.00460

Song, Z. F., An, J., Fu, G. H., and Yang, X. L. (2011). Isolation and characterization of an aerobic denitrifying Bacillus sp. YX-6 from shrimp culture ponds. Aquaculture 319, 188-193. doi: 10.1016/j.aquaculture.2011.06.018

Stein, L. Y., and Klotz, M. G. (2016). The nitrogen cycle. Curr. Biol. 26, R94-R98. doi: $10.1016 /$ j.cub.2015.12.021

Stevens, R. J., Laughlin, R. J., and Malone, J. P. (1998). Soil pH affects the processes reducing nitrate to nitrous oxide and di-nitrogen. Soil Biol. Biochem. 30, 1119-1126. doi: 10.1016/S0038-0717(97)00227-7

Sun, Z. Y., Lv, Y. K., Liu, Y. X., and Ren, R. P. (2016). Removal of nitrogen by heterotrophic nitrification-aerobic denitrification of a novel metal resistant bacterium Cupriavidus sp. S1. Bioresour. Technol. 220, 142-150. doi: 10.1016/j. biortech.2016.07.110

Szukics, U., Abell, G. C., Hodl, V., Mitter, B., Sessitsch, A., Hackl, E., et al. (2010). Nitrifiers and denitrifiers respond rapidly to changed moisture and increasing temperature in a pristine forest soil. FEMS Microbiol. Ecol. 72, 395-406. doi: 10.1111/j.1574-6941.2010.00853.x

Van den Berg, E. M., Boleij, M., Kuenen, J. G., Kleerebezem, R., and Van Loosdrecht, M. C. M. (2016). DNRA and denitrification coexist over a broad range of acetate/N-NO3- ratios, in a chemostat enrichment culture. Front. Microbiol. 7:1842. doi: 10.3389/fmicb.2016.01842

Vidal, E. A., Alvarez, J. M., Viviana, A., Eleodoro, R., Brooks, M. D., Gabriel, K., et al. (2020). Nitrate 2020: Thirty years from transport to signaling networks. Plant Cell 32, 2094-2119. doi: 10.1105/tpc.19.00748

Wang, C., Wang, X., Pei, G. T., Xia, Z. W., Peng, B., Sun, L. F., et al. (2020). Stabilization of microbial residues in soil organic matter after two years of decomposition. Soil Biol. Biochem. 141:107687. doi: 10.1016/j.soilbio.2019. 107687

Xia, L., Li, X., Ma, Q., Lam, S. K., Wolf, B., Kiese, R., et al. (2020). Simultaneous quantification of $\mathrm{N} 2, \mathrm{NH} 3$ and $\mathrm{N} 2 \mathrm{O}$ emissions from a flooded paddy field under different $\mathrm{N}$ fertilization regimes. Glob. Change Biol. 26, 2292-2303. doi: $10.1111 / \mathrm{gcb} .14958$

Yan, J. W., Su, H. T., Kuang, X. X., Luo, L. X., Zhou, W., and Zhou, S. Q. (2021). Characteristics and mechanism of simultaneous nitrate and phenol removal by a newly isolated Cupriavidus oxalaticus T2. Int. Biodeter. Biodergr. 161:105234. doi: 10.1016/j.ibiod.2021.105234

Yang, X. P., Wang, S. M., and Zhou, L. X. (2012). Effect of carbon source, C/N ratio, nitrate and dissolved oxygen concentration on nitrite and ammonium production from denitrification process by Pseudomonas stutzeri D6. Bioresour. Technol. 104, 65-72. doi: 10.1016/j.biortech.2011.10.026

Yoon, S., Cruz-García, C., Sanford, R., Ritalahti, K. M., and Löffler, F. E. (2015). Denitrification versus respiratory ammonification: environmental controls of two competing dissimilatory NO3-/NO2- reduction pathways in Shewanella loihica strain PV-4. ISME J. 9, 1093-1104. doi: 10.1038/ismej.201 4.201

Yu, M. J., Meng, J., Yu, L., Su, W. Q., Afzal, M., Li, Y., et al. (2019). Changes in nitrogen related functional genes along soil $\mathrm{pH}, \mathrm{C}$ and nutrient gradients in the charosphere. Sci. Total Environ. 650, 626-632. doi: 10.1016/j.scitotenv.2018.08. 372

Zhang, J., Lan, T., Müller, C., and Cai, Z. (2015). Dissimilatory nitrate reduction to ammonium (DNRA) plays an important role in soil nitrogen conservation in neutral and alkaline but not acidic rice soil. J Soils Sediments 15, 523-531. doi: 10.1007/s11368-014-1037-7

Zhao, B., Cheng, D. Y., Tan, P., An, Q., and Guo, J. S. (2018). Characterization of an aerobic denitrifier Pseudomonas stutzeri strain XL-2 to achieve efficient nitrate removal. Bioresour. Technol. 250, 564-573. doi: 10.1016/j.biortech.2017.1 1.038

Conflict of Interest: The authors declare that the research was conducted in the absence of any commercial or financial relationships that could be construed as a potential conflict of interest.

Publisher's Note: All claims expressed in this article are solely those of the authors and do not necessarily represent those of their affiliated organizations, or those of the publisher, the editors and the reviewers. Any product that may be evaluated in this article, or claim that may be made by its manufacturer, is not guaranteed or endorsed by the publisher.

Copyright (C) 2021 Huang, Tie, Xie, Jiang and Li. This is an open-access article distributed under the terms of the Creative Commons Attribution License (CC BY). The use, distribution or reproduction in other forums is permitted, provided the original author(s) and the copyright owner(s) are credited and that the original publication in this journal is cited, in accordance with accepted academic practice. No use, distribution or reproduction is permitted which does not comply with these terms. 